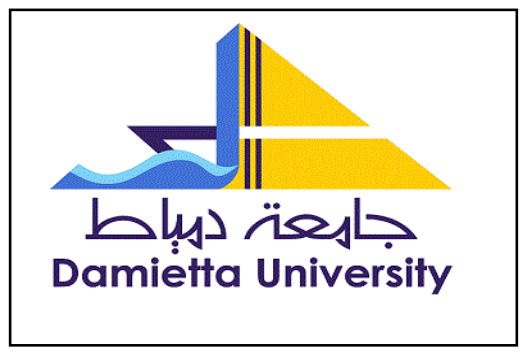

$$
\text { كلية الآداب }
$$

\title{
يهود المغرب قبل الاحتلال الفرنسي
}

\author{
إعداد الطالبة \\ غادة حمدي عبد السلام \\ كلية الآداب - جامعة دمياط \\ Y. 10
}


(280) 
أن الاهتمام بتاريخ وحضارة اليهود المغاربة يندرج

ضمن المحاولات الجادة لكل باحث عربي لرصد ظاهرة إمكانية التعايش السلمي تحت سقف واحد بين مختلف الأديان .

لذلك إتسع خلال القرن الماضي حقل الأبحاث المعنية بدراسة علاقة اليهود بالمسلمين في بلدان المغرب العربي بصفة عامة ، وفي المغرب بصفة بهابة خاصة ، حيث كان لتأسيس دولة إسرائيل ، وتزايد حدة النزاع العربي الإسرائيلي ، وهجرة أعداد كبيرة من يهود المغرب لإسرائيل ، أثره في تزايد إهتمام الإنيا الباحثين بدراسة تاريخ يهود المغرب .

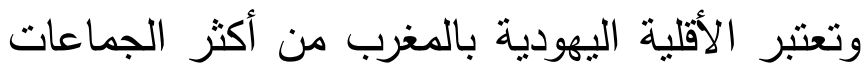

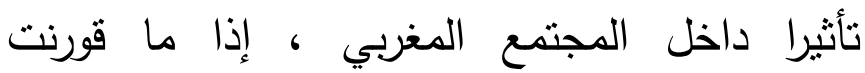
بالأقليات اليهودية الأخري في بلدان المغرب التبر العربي (تونس - الجزائر - ليييا ) ، ويبدو ذللك التأثنر 
واضحا في المجال الاقتصادي والثقافي ، والنشاط السياسي والاجتماعي لذا تضافرت العديد من العوامل ، كما ساهم حسن التعايش بين اليهود والمغاربة بروح من الاحترام والاتزان في إرساء جو من الثقة بين الطرفين ، كما أدي إنصهار اليهود في الذات المغربية بسهولة دون حاجز أو عائق تطبعة إختلاف العقيدة ، إلي إغناء كلا من الثقافة الإسلامية والعبرية ، وإزدهار الأنشطة الاقتصادية والاجتماعية لليهود والمسلمين علي حد سواء ، فالكل يخضع لمنظومة قانونية واحدة ترعي

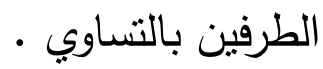
ويمكننا القول أن الحضور اليهودي بالمغرب قد تغلغل في مختلف نواحي الحياة بالبلاد بدءا من الملاحات (الحي اليهودي ) داخل المدن المغربية العتيقة ، وصولا إلي مساهماتهم إلي حد كبير في السياسة المغربية وإلتصاقهم بالحكام والأجانب . 
وكان ذلك الوضع مردة الأساسي إلي الإطار القانوني المعتدل الذي إتخذته السلطات الحاكمة تجاه اليهود بالإضافة إلي سماحة الإسلام . وبناءا عليه فقد تم تخصيص ذللك البحث لإلقاء الضوء علي وضع اليهود المغاربة في فترة ما قبل الحماية الفرنسية عام Y / 19 م ومدي تأثرهم وتأثثرهم علي المجتمع المغربي • وذللك وفق العديد من التحولات والتغيرات الاقتصادية والاجتماعية والسياسية التي طرأت علي بنايات المجتمع المغربي

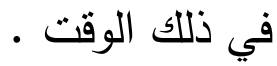
هذا بالإضافة إلي محاولة أعادة قراءة وكاتبة شطر هام من تاريخ المغرب الخاص ببداية التواجد اليهودي بأرض المغرب ، وعلاقة اليهود بالمغاربة ومراحل تطور تللك العلاقة وتأثيرها علي المجتمع المغربي قبل فترة الاحتلال الفرنسي لذا ركز ذلك البحث علي النقاط التالية : - الت

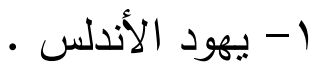


r- بداية التواجدي البهودي بالمغرب.

r- التغيرات الاقتصادية

ع - التغيرات الاجتماعية والقانونية .

0- علاقة يهود المغرب بأرض فلسطين .

يهود الأندلس : بله

عاثر اليهود في بلاد الأندلس قبل الفتح

العربي الإسلامي لها كطبقة مغلوبة علي أمرها ، فقد

هربوا إلي أسبانيا ، واليونان ، وشمال أفريقيا ، عقب الب

تحطيم هيكلهم الثاني إلا أن أكثر العناصر المهاجرة

اتجهت نحو أسبانيا بسبب ضعف سلطة الكنيسة بها

وبعدها عن الدولة البيزنطية '.

وقد اثتغل اليهود بأسبانيا بالنشاط الاقتصادي

والأعمال الحسابية ، كما قام بعضهم بالعمل في بلي

التجارة ، وظن اليهود غداه إستقرارهم بالبلاد أنهم

بأمان إلا أن ذلك لم يحدث فقد كانوا مكررهين من

' - عبد الجليل شلبي : اليهود واليهودية ، القاهرة ، دار أخبار

اليوم ، 199V ، ص الئل 100

(284) 
قبل أهل البلاد ، وذلك بسبب إختلاف عقيدتهم

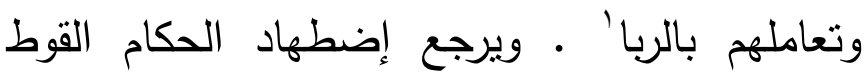
لليهود بأسبانيا بسبب نشاطهم التبشيري وتشجيعهر

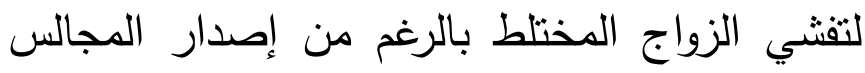
الكنسية قرارات بمنع زواج المسيحيين من اليهود ‘. ويذكر بعض المؤرخين أن اليهود بأسبانيا كانوا علي صلة بأبناء ملتهم في الثمال الأفريقي فقد كانوا علي علم باخبار الحرية الدينية التي تمتع بهاء

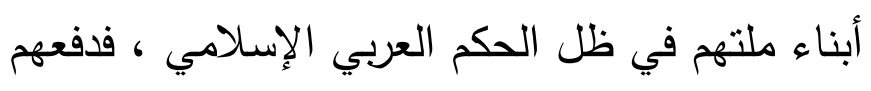
هذا إلي اسقاط الدولة القوطية ، وتدبير المؤمرات

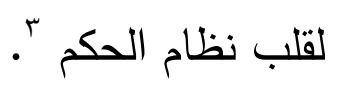
وقد نتج عن ذلك أن عقد أعضاء مجمع طليطلة اجتماع للحكم علي اليهود للتخلص منهم ، ' - عطية القوصي : اليهود في ظل الحضارة الإسلامية ، جامعة

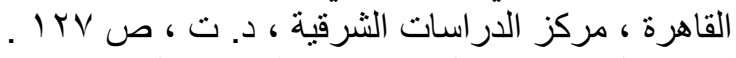

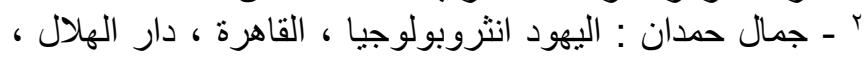

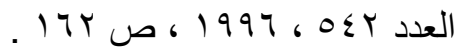

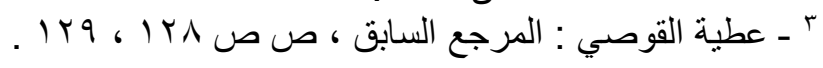


كما فرضت عليهم عقوبات بغية تتصيرهم ، مما كان له أنز في تعاون اليهود مع الفتح العربي الإسلامي عائي

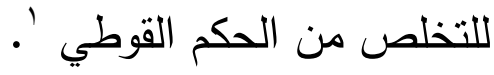
وفي عام الVII م تم الفتح العربي الاسلامي لأسبانيا علي يد طارق بن زياد ، واقيمت في أسبانيا

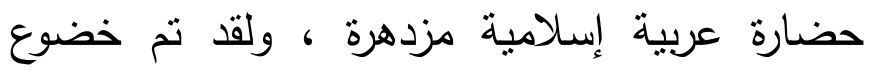

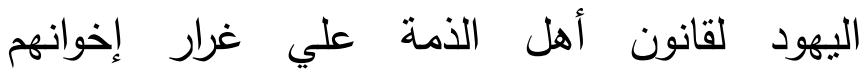

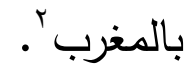

وقد عاش اليهود في الأندلس جنبا إلي جنب

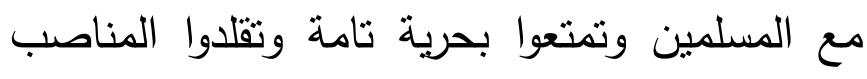
العليا في الدولة حيث ولا هم العرب كبري المدن

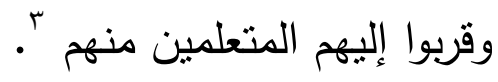

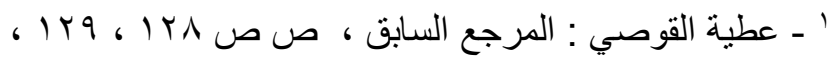
$|r|$ r ـ - زينب حسن أبو زيد : اليهود في الأندلس في عصر المرابطين

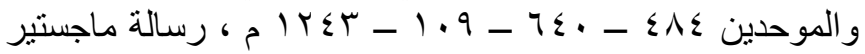

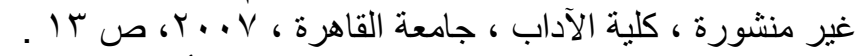

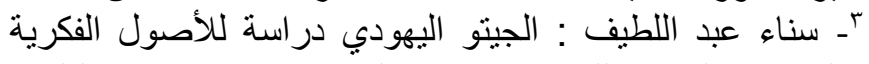

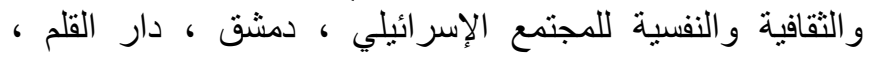


ولم تقرض الدولة الإسلامية في كافة ربوعها

علي أهل الذمة بالإقامة في أماكن محددة فقد نشأت

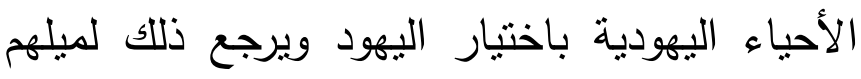

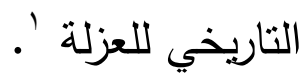

كما عاش اليهود تقريبا في كل الددن والقري

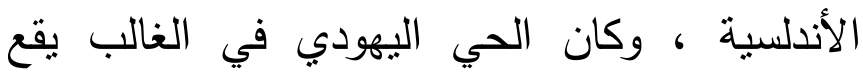
بالقرب من القصر الملكي ، إلا أن التوزيع السكاني

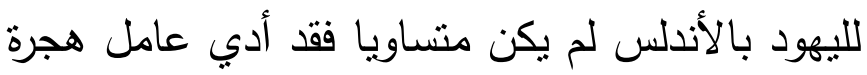
اليهود من القري للمدن من أجل العمل بالتجارة إلي هالي

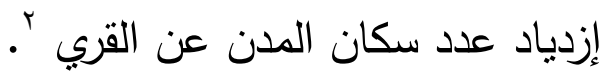
كما إزداد أيضا عدد اليهود من بعض اليض المدن

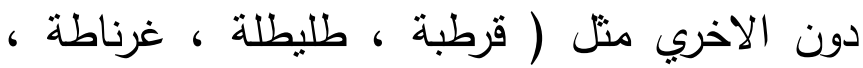
اشبيلية ) وإنقست إحياء اليهود في المدن الأندلسية

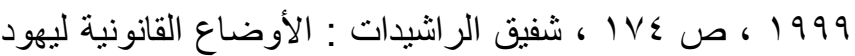

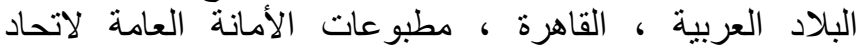

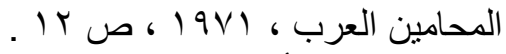

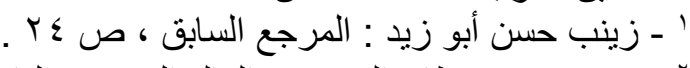

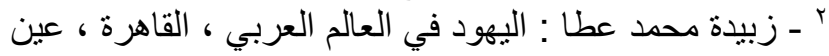

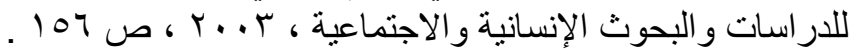


إلي أحياء كبيرة وأخري صغيرة ، وسكنت العائلات ذات الأصول العريقة داخل الأحياء الكبري وتميز أفرادها بثرائهم وإرتفاع مستوي ثقافتهم وإتصالهم برجال البلاط ، وكان يتم اختيار القضاه والأحبار ورئيس أعضاء مجلس الطائفة من أبناء تلك الطبقة' . ويمكننا القول أن إختيار رئيس الطائفة كان يتم عن طريق نرشيح الجماعة اليهودية نفسها ، وكان رئيس الطائفة يحمل لقب ( الناسئ ) )َ وبساعده مجلس يتكون من سبعة شيوخ كان ذلك المجلس يجتمع للتشاور في أمور الجماعة ، وكان من بين مهام رئيس الجماعة ومجلس الطائفة تحديد أسعار

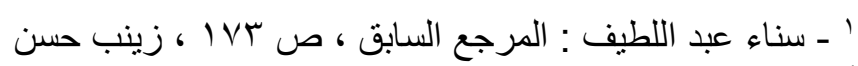

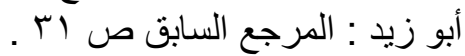

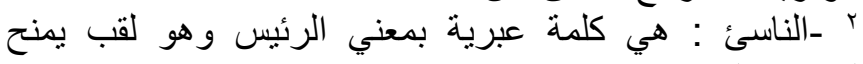

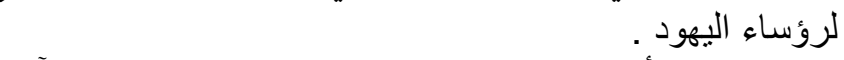
محمد جلاء أدريس : مؤثرات عربية وإسلامية في الآداب

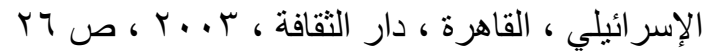


المواد الغذائية ، قمع الغش ، منع الأطفال من ممارسة الحرف قبل وصولهم سن التعليم الديني' كما يمكننا القول أن رئيس الطائفة وأعضاء المجلس كانوا لا يتقاضون أيه رواتب مقابل تأدية وظائفهم فهم من ذوي المال ، ولمجلس الطائفة صندوق توضع فيه الضرائب التي تفرض علي بيع اللحوم والخمور وإقامة الأعراس ، كما تودع فيه الصدقات والغرامات ، ومن إيرادات صندوق الطائفة يوفر المجلس أجور الحاخامات والعاملين في المعبد واحتياجات الفقراء ، وبعد تكوين مجلس الطائفة يتم تعيين القضاه ، وتتكون المحكمة اليهودية من ثلاثنة قضاه ، لابد أن تتوافر فيهم شروط الإلمام بالشريعة

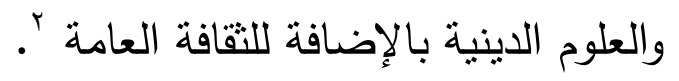

كان لليهود قضائهم الخاصة بهم ولا تتذخل الإدارة الإسلامية في شئونهم إلا إذا وقع خلاف بين

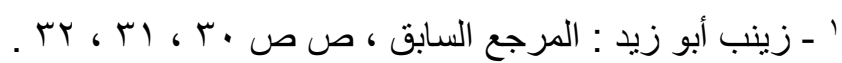

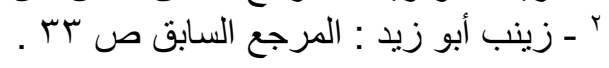


اليهودي والمسلم ، ففي تلك الحالة تعرض القضية علي القضاء الإسلامي '. ولقد تمتع القضاه في الأندلس بمكانة أكبر من تلك التي كانت لنظرائهم في المشرق بل كانت منزله القاضي تعلو منزلة الرابي ، ويعاون القاضي الكتاب الموتقون اللذين يتولون كتابه نصوص القضايا وتسجيل الأحكام ، وبتلقي هؤلاء أجورهم من صندوق الطائفة '. أما في مجال المال فقد حصل يهود الأندلس علي امنيازات كثيرة تحت الحكم الإسـامي ، فقد عملوا كسفراء في عدد من الأقطار العربية ، كما عملوا بالتجارة الخارجية وجباية الرسوم الجمركية والتفاوض نيابة عن الملوك مع التجار الأوروبيين'ّ

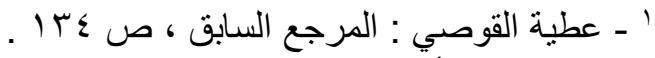

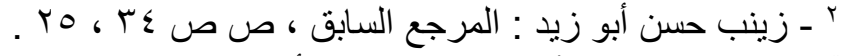

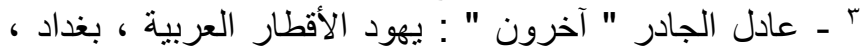

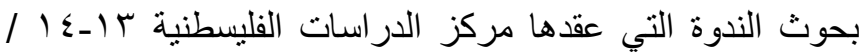

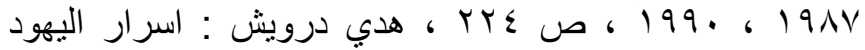


وقد امتهن يهود الأندلس العديد من الحرف

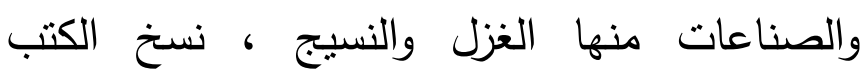

وتجليدها ، وفي عهد المرابطين والموحدين نشطت

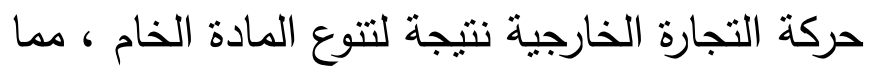

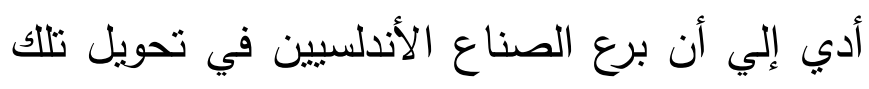

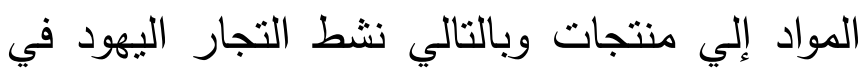
تصريف ثلك المنتجات وأيضا استنيراد ما يحتاجه

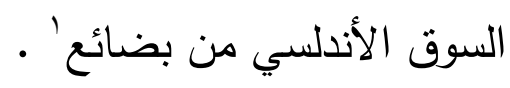

وعلي المستوي الثقافي والعلمي أزدهرت

الحركة الفكرية اليهودية في الأندلس في ظل الحاكم

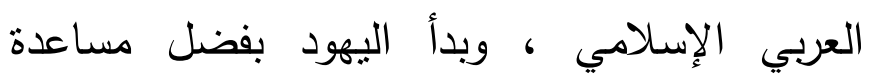

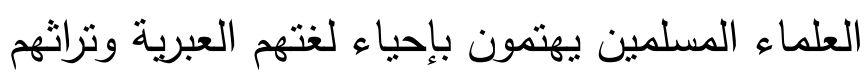

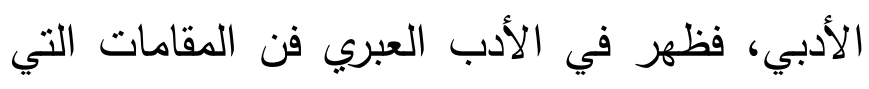

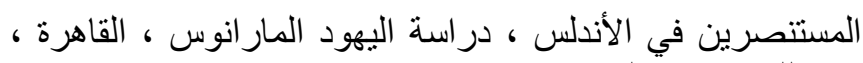

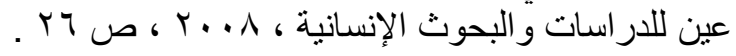

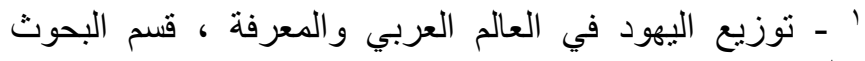

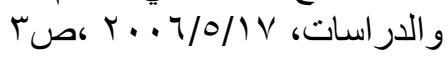

www.Aljazeera.net 
كانت تحاكي مقامات (الحربري - بديع الزمان

'الهمذاني)

كما نشطت الدراسة التلمودية وظهر عدد لا

بأس به من علماء اليهود اللذين تتلمذوا علي يد

علماء المسلمين أمثال ( بن رشد ) فبدأ بيسح نجم الثعر العبري والأناشيد الدينية ، وقد درج عدد من العلماء والثعراء اليهود علي استخدام اللغة العربية في كتاباتهم ، ولكن بحروف عبرية أمثال ( موسي

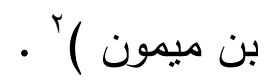

ولم تكن معرفة الأدباء اليهود باللغة العربية

معرفة سطحية ، بل إنهم تبحروا في بلاغاتها وآدابها ، وقد نتج عن ذلك أن نال الشعر العبري مواطن خصبة لم تطأها قدمة من قبل غيرت من قالبه

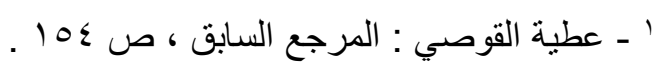

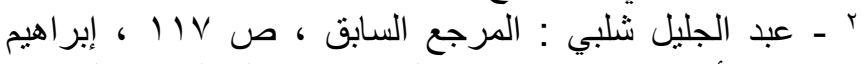

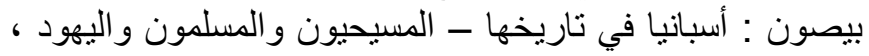

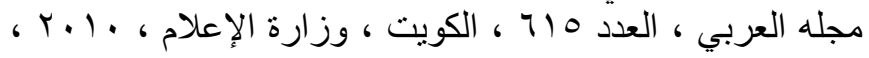

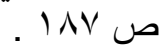


وتقنياته ، فأصبح شعر (البيوط ) ' بنظم وفق تقنيات الثعر العربي الذي كان بعاصره ، كما أصبحت اللغة العبرية تتسج علي منوال اللغة العربية إلا ما كان من الفروق الخاصة بحركات المد الطوبلة والقصيرة ، كما استهوي الثعراء اليهود البحور العربية ، وقد ترتب عليه أن أصبح الثعر من بين الأنماط التعبيرية المفضلة في المجتمع البهودي بالأندلس '، ونستتتج مما سبق أن اليهود بالأندلس كانوا أحسن حالا من غيرهم في البقاع الأخري من حيث الأمن والاستقرار ، وقد لعبوا بما يتميزوا به من وضع قانوني دورا هاما في إزدهار حياه البلاد الاقتصادية ،

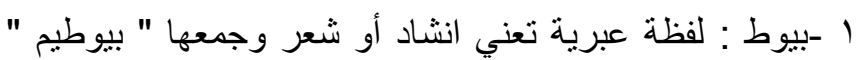

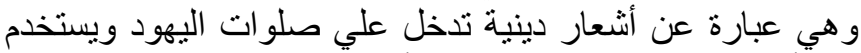
فيهاً ألفاظ من العهد القديم و اللغة الأر امية.

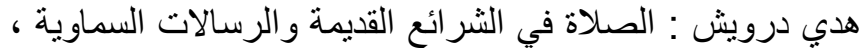

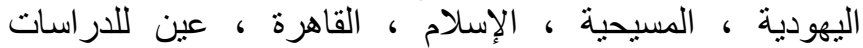

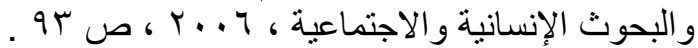

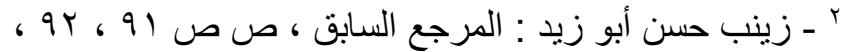

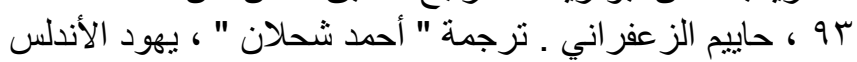

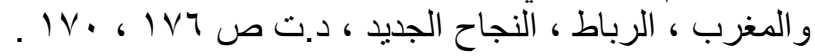


بل وفي الثئون العامة ، وكما منحهم الرخاء والحرية الفرصة لطلب العلم وبلوغ مراتب عليا في الآداب العبرية والعربية الأندلسية ، مما مكنهم من أن يأثروا بتأثنر كبير في تطور الفكر اليهودي • وفي عام ra ا ا تعرض اليهود إلي حملة قتل وتشريد عقب سقوط الحكم العربي الإسلامي بالأندلس ، رافق سقوط غرناطة قيام كلا من الأسبان والبرتغاليون بإضطهاد اليهود اللذين لم يكن أمامهم سوي الهجرة أو التتصير ' '. وبناءا عليه خرج اليهود من ولاية قشتالة وجزر صقلية وسردانية ، واتجهوا نحو الجنوب (المغرب الإسلامي ) متخذين لإقامتهم الجديدة مراكز عديدة ، فكانت النتيجة المباشرة لذلك أن برزت ملامح الوجود اليهودي في الغرب بشكل واضح '.

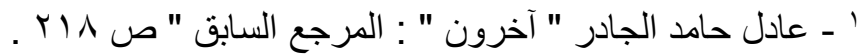

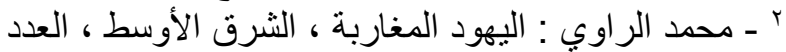

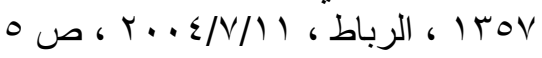
www.asharqlawsat.com 


\section{باية التواجد اليهودي بالمغرب}

تعتبر بداية التواجد اليهودي في المغرب من بالئن

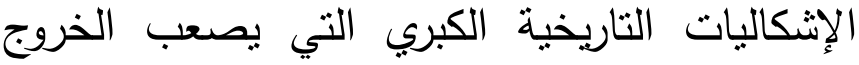

منها بنتائج قطعية ، إذ يصعب علي أب مهتم بناريخ

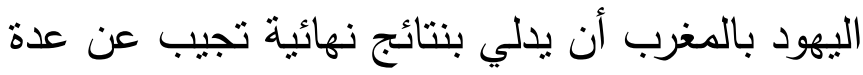

فرضيات مرتبطة بالجانب التأصيلي لهذه المسألة .

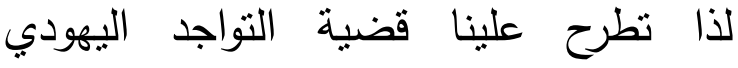

بالمغرب العديد من النسؤالات أهمها ما

$$
\text { يلي : }
$$

هل اليهود بالمغرب من أصول أجنيية وافده ،

أم هم من أصول محلية تابعة من الأراضي المغربية

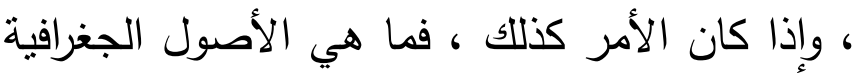

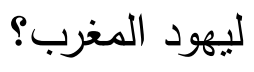

وهل السألة اليهودية في البلاد المغربية

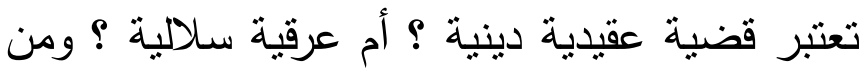


جانب آخر ما السر في التواجد اليهودي المكثف في المغرب عبر تاريخه؟ وكيف كانت علاقة هذه الثريحة الاجتماعية مع باقي فئات المجتمع المغربي ما قبل الإسلام ، وما بعد وصول الفاتحين العرب ، وأيضا في فنرة الحماية الفرنسية علي البلاد ، بل كيف كانت الجهات الرسمية الحاكمة للبلاد المتمثلة في السلطة المخزنية تتظر لمسؤليتها تجاه مختلف العناصر اليهودية ' ولإجابة علي تلك التساؤلات يمكننا القول أنه يسود اعتقاد في بعض المصادر التاربخية أن الطائفة اليهودية بالمغرب هي أول مجموعة ( غير بربرية )'

$$
\text { ـ ـ عبد الله استيتيو: اليهود في المغرب، ص ץ }
$$
www.aljabiabed.com

ك ـ البربر : هم أقدم سكان المغرب وهم عرب من أصول كنعانية

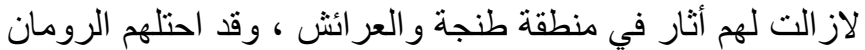

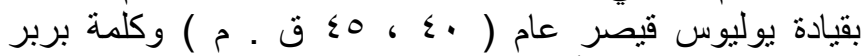
يرجعها البعض إلي أصل لاثيني قديم بمعني المتعلثم في كلامدا

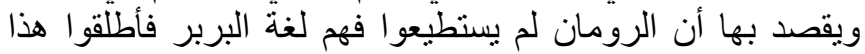

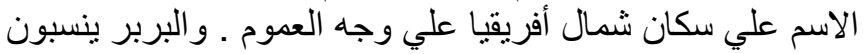

\section{(296)}


قدمت للبلاد مند ما يناهز ب ج قرنانا ، أي في أعقاب

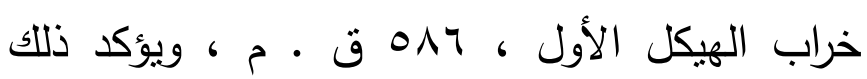

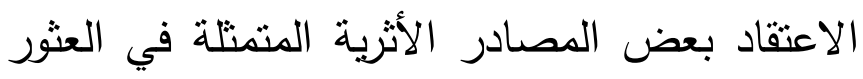
علي أحجار في كلا من ( طنجة - فاس) التي وضعت كعلامات من قبل ( يواب بن سوريا ) قائد جيش الملك داود ، أثناء دخوله المغرب متعقبا نخبة من العائلات الفلسطينية الأصل '. لئل

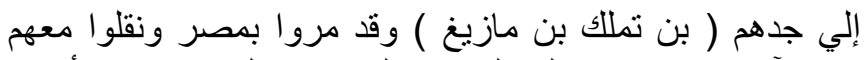

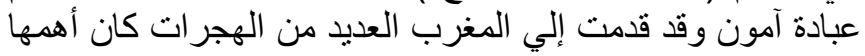

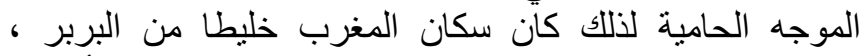

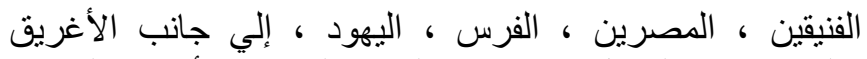

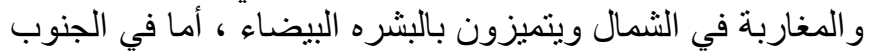

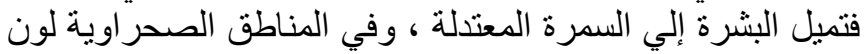

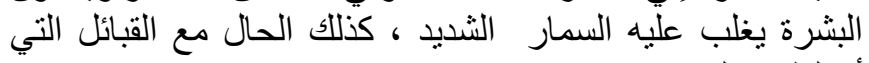
محمد عبد الحميد الحمد : دور اليهود في الحضلارة الاسلامية د.

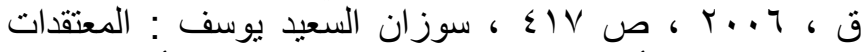

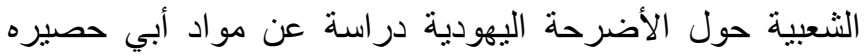

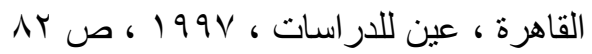

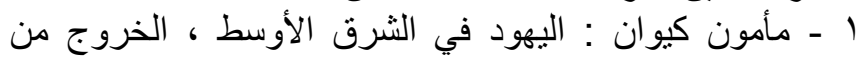

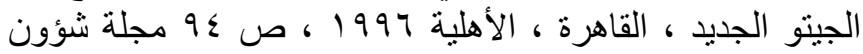

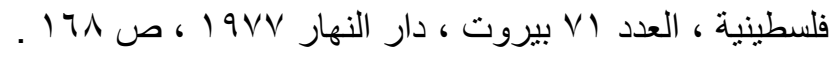


وبالإضافة إلي ذلك تشهر مجموعة من

النقوش المكتوبة بالعبرية علي شواهد القبور والتي تم

العثور عليها في الأطلال الرومانية تؤكد علي تمركز

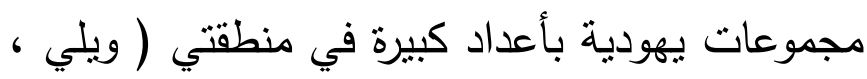

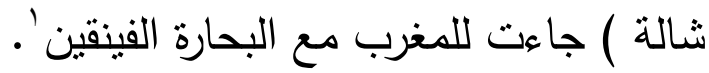

وقد عرف الوجود الروماني ( المسيحي )

بالمغرب نشاطا دينيا مكثقا في منطقتي ( سوس ، درعة ) وبالرغم من ذللك تمكن اليهود بفضل إختلاطهم المباثر بالقبائل البربرية من اقتتاع عدد من تلك القبائل بكل الوسائل من اعتناق الديانة

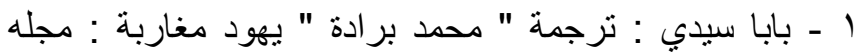

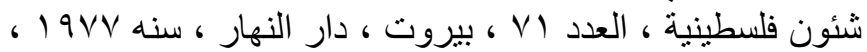

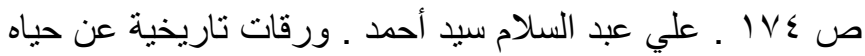

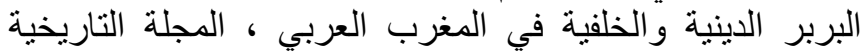

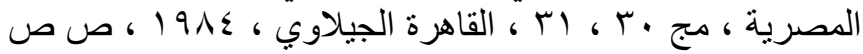


اليهودية، فتأثزت بهم قبائل ( جراده ، نفوسه مندلاوه ) وذللك قبل مجئ الفتح الإسلامي '. إلا أن الرومان وقفوا في وجه اليهود بالمرصاد وعملوا بدورهم علي القيام بعملية تبثير للدين المسيحي في صفوف كلا من اليهود والبربر ، وذلك باعتبار أن الدين المسيحي دينا رسميا يندرج

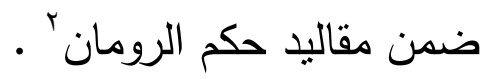
وبناءا عليه يمكننا القول أن اليهودية دخلت إلي المغرب منذ ما قبل الميلاد إلي مناطق سكن البربر في الجنوب وذللك من خلال التأثيرات المباشرة بين الجماعات البربرية واليهودية وقد تميز يهود تلك المناطق بتحدثهم اللغة الأمازيغية وبأنهم يشبهون

' - عادل حامد الجادر : ( آخرون ) ، المرجع السابق ، ص YYY r- سهام لعسري : نبذة عن اليهود في تاريخ المغرب ، ص ا www.anfasse.org 
البربر في طرق حياتهم وعاداتهم وتقاليدهم ولا يختلفون عنهم إلا في الديانة '.

وقد أدي تمتع اليهود بكامل حريتهم في عهد

الرومان إلي ازدياد اعدادهم ، واحترافهم كل ركائز

الحياة الاقتصادية من رعي وصناعة علاوه علي

التجارة وخاصة تجارة الرفهيات ولم يقبل اليهود علي الزراعة مهتمين بمهن أخري تدر عليهم أرباح سريعة

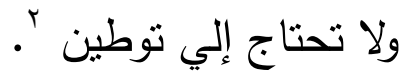

وبنظرة عابرة علي ما سبق نجد أنفسنا أمام

فراغ كبير حيثما يتعلق بالفترة الفاصلة بين الحكم الروماني وبداية الفتح العربي الإسلامي للمغرب علي يد عقبة بن نافع عام س^ף م الذي وجد مقاومة

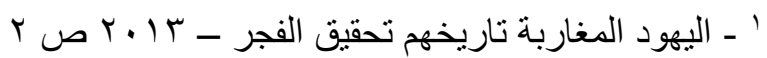
www.elfajr.net

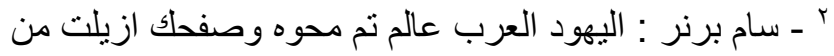

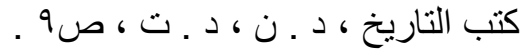

(300) 
شديدة من نصاري البربر وترحيبا من القبائل

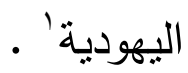

وعندما استقر الحكم العربي الإسلامي بالبلاد

تتعم اليهود بالحرية الكاملة وتم تحديد وضعيتهم الدينية والاجتماعية في إطار التشريع الخاص بحماية أهل الذمة علي يد أدريس الأول مؤسس الدولة

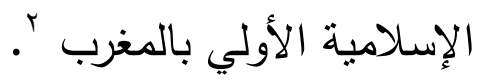
وفي عهد أدريس الثاني أصبحت مدينة فاس مركزا للنقافة اليهودية فظهرت بها الأرهاصات الأولي للنحو والثعر العبري ، كما أصبحت مركزا للاراسات اللغوبة والدينية وكذلك الدراسات التلمودية بعد مدينة القيروان مما أدي إلي أن ظهرت بها نخبة من رجال الدين المتميزين كالحاخام ( اسحق الفاسي ) '•.

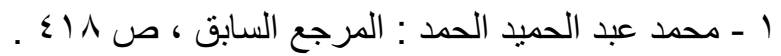

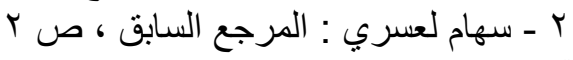

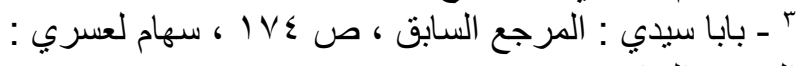

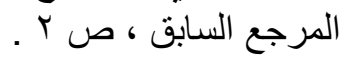


وفي عام (1.0.0 ) أسس ( محمد بن

الثربف الحسني ) الدولة العلوية في (فاس - مكناس

- سلا ) وأعطي الحرية لليهود اللذين صاروا يتاجرون مع (صقلية ، البندقية ، برشلونه ) فأصبحوا

،يتوردون (البهارات ، المرايا ، النحاس ، الفولاز ، الته

الأسلحة ، بينما كانوا يصدرون ( الحديد ، القطن الكن ل

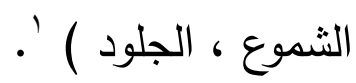

ونستتتج مما سبق أن اليهود في بلاد المخزن

(المناطق التي تخضع للسلطة المركزية ) عاشوا

احرارا واكتسبوا الكثير في عادات وتقاليد المسلمين كان أهمها إيمانهم بفكرة تعدد الزوجات علي الرغم

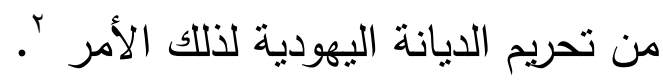

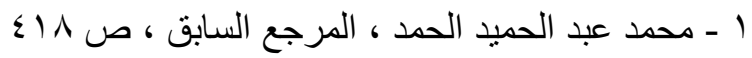

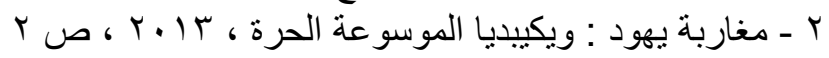


أما بالنسبة ليهود الجنوب ، فقد اختلفت

أوضاعهم عن يهود الشمال اللذين اكتسبوا صفات

جيرانهم من البربر ، لذلك كانوا يعانون من التزمت

وفقدان التشامح الديني ، كما أنهم اكتسبوا الكثير من

عادات وثقاليد البربر ، كان من أهمها الإيمان

بالخرافات والتتبوء بالسحر ، لذلك أفرطوا في استخدام

الأحجبة وصناديق التعوبذات والأثكال والرموز كما

انتشرث لديهم ظاهرة زيارة القبور واسنترك لدي

$$
\text { الأولياء الصالحين ' }
$$

وقد عاش أهل الذمة بالمغرب في عهد

المرابطين حياة اجتماعية ودينية خضعت في بعض الأحيان للأوضاع الاقتصادية فثهدوا نتيجة ذلك فترة في الثدة حيث فرضت عليهم بعضا من القيود ، كان منها عدم السماح لهم بالإقامة والعيش بمدينة مراكث

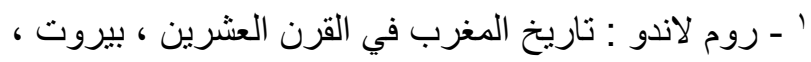

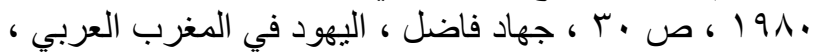

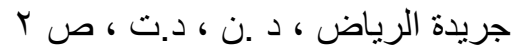

Www.alrigabhi.com 


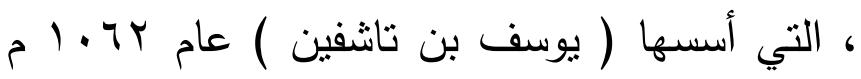
إلا في أوقات النهار فقط لقضاء أعمالهم التجارية '. وعلي وجه العموم يمكننا القول أن اليهود في عهد المرابطين لم بشهدوا ازدهارا فكربا أو ثقافيا بل تراجعت في ذلك الوقت مكانة اللغة العبرية ، كما قل الإنتاج الأدبي وعلي الرغم من ذلك لم يبجل التاريخ

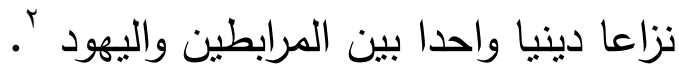
ونستتنج مما سبق ، أن إنصهار العنصر اليهودي في الحياة السياسية والنقافية والاجتماعية في ، المجتمع المغربي بشكل أو بصورة تنشط وتختفي كان حسب الظروف السياسية والاجتماعية التي عرفها المغرب ، وحسب طبيعة الحكم فيه ، كما يمكننا القول أن العنصر اليهودي لم يكن بالنسبة

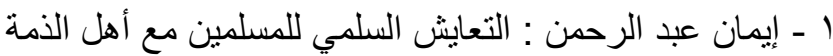

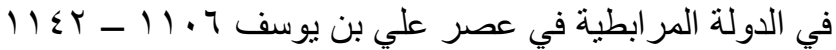

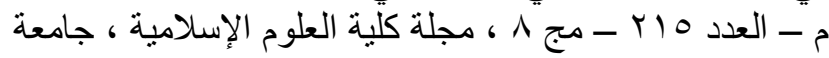

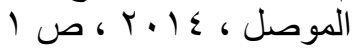

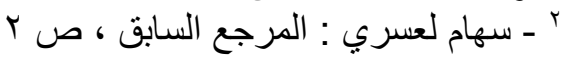


للمغرب والمغاربة عنصرا دخيلا بل أنهم شكلوا حتي قبل بروز حكم الدولة الإسلامية بالبلاد عنصرا

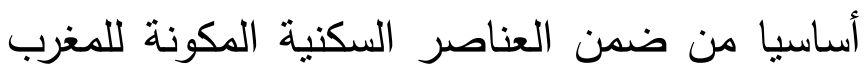
وفي نهاية الأمر ، يمكننا القول أن الطائفة اليهودية

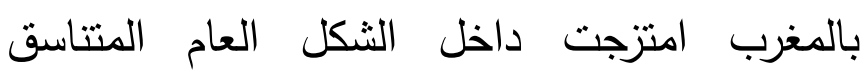
للفسيفسائية الدينية والثقافة للبلاد ' لـابل وفي عام الإسلامي بالأندلس ، وتعرض اليهود بالأندلس

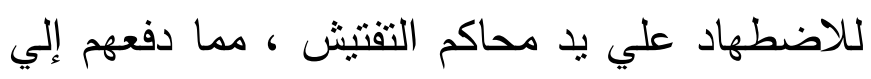

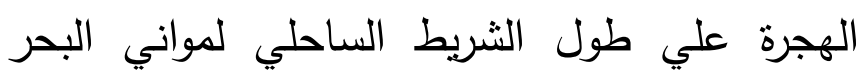

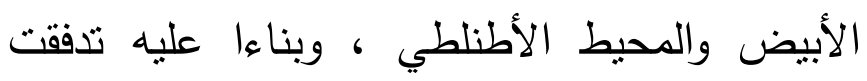
علي المغرب موجه كبيرة من المهاجرين اليهود اللذين استقروا في ( مكناس ، فاس ، سلا ، تطوان) بينما

1 - التاريخ اليهودي : ص 1 www.jimenqexperience.org 
استوطن يهود البلاد الأصليون في المناطق الجبلية وتخوم الصحراء' .

وكان اليهود المهاجرون يشعرون بالاعتزاز

والانتماء للمدن المغربية التي آواتهم لاي هروبهم من بندرون بالاعران الأسبان ، وقد التسم وضعهم بقدر من الاستقرار ونجحوا في الاندماج في المجتمع المغربي تحت الحكم العربي ، الذي غير من أوضاعهم وأصبحوا

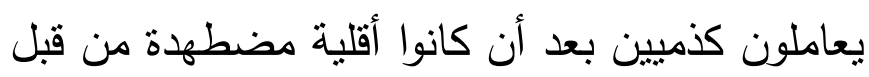

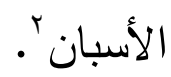
وبناءا عليه يمكننا تقسيم يهود المغرب إلي فئتين الأولي ( المغورشيم ) أي المهجرون وتمثلوا في بئي

' ـ ماهر سمك : اليهود في المغرب ، القاهرة ، دار الحرية ، المعال

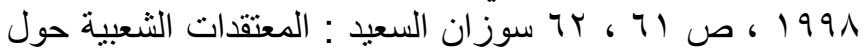

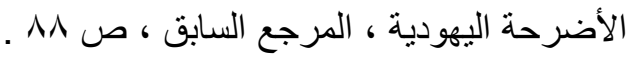
r - ديمة عبد الرحيم : يهود المغرب العربي في في إسر ائيل ، مجله

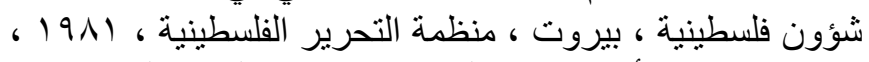

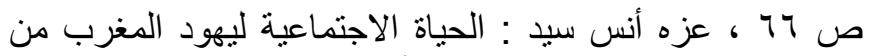

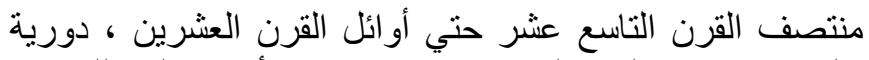

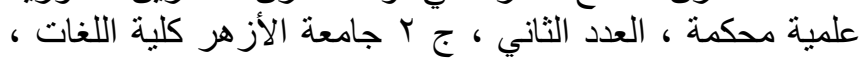

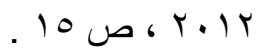

\section{(306)}


العنصر الايبيري الوافد من أسبانيا ، أما الفئة الثانية تسمي (التوشفيم ) أي المحليون والمقصود بهم سكان الانيان

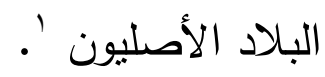

وقد إختلفت المجموعتان العرقيتان من حيث

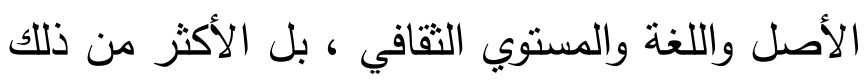

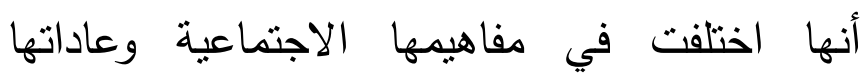
وتقاليدها، حيث احتفظت طائفة المهاجرين بالتقاليد

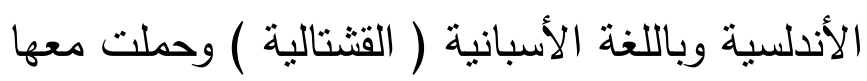

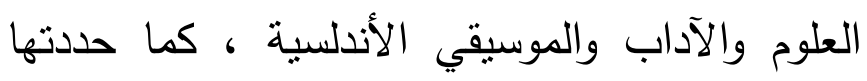
أعرافهر التي جعلت منهم عكس أخوانهم اليهود المحليون مجموعة إجتماعية ثقافية مميزة '. وقد أدي التميز الفكري والتقافي ليهود أسبانيا بالإضافة لسماحة الإسلام إلي تفوقهم في المجال 1 - آسفي مدينة يهود بدون ملاح - مجله سفا باريس ، العدد

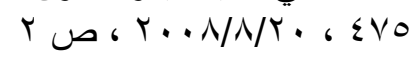

www.safipress.com

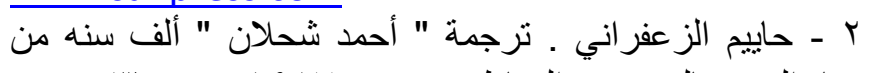

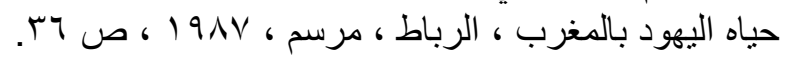


التجاري وقيامهم بربط اتصالاتهم التجارية بالواحات

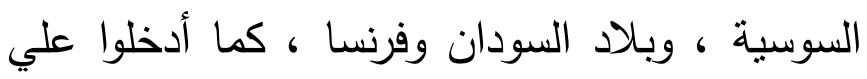
المغرب العديد من المهارات الصناعية والحرفية

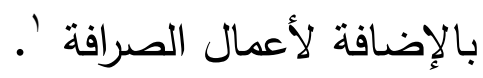
أما اليهود المحلين فقد كانوا يتحدثون اللغة الهنة البربرية العربية ، وقد اندمجوا إندماجا كليا مع سكان

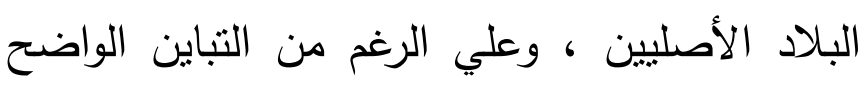

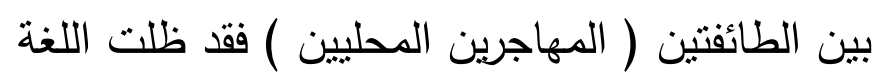

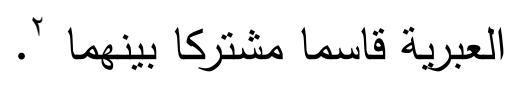

كان يهود المغرب منتبهين إلي تتوع أصولهم

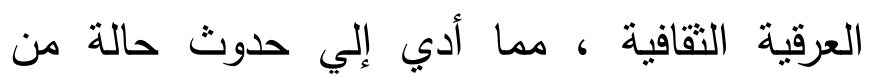

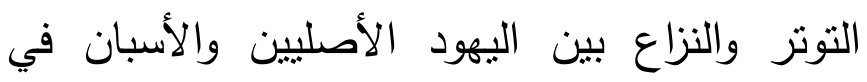

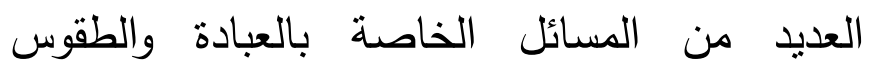

$$
\begin{aligned}
& \text { ' ـ سهام لعسري : المرجع السابق ، ص ب روم لاندو : المرجع }
\end{aligned}
$$

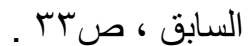

$$
\begin{aligned}
& \text { r - مأمون كيوان : المرجع السابق ، ص ص ؟ } 9 \text { ، ، } 90 \text {. } \\
& \text { (308) }
\end{aligned}
$$


والقوانين وقد انتهي ذلك النزاع بأنتصار اليهود الجدد

اللذين أخذوا قيادة الجماعة اليهودية '.

وقد يكون من المفبد هنا أن نشير إلي أوجه

التسامح الإسلامي تجاه اليهود الأصليين وكذلك إزاء

من لحق بهم من مهاجرين أسبان فلم تحرمهم السلطة السياسية أو الإدارية في كامل أطراف المغرب من ممارسة أنشطتهم بكامل الحربية '.

التغيرات الاقتصادية :

تتفق العديد من الدراسات التي تتاولت

أوضاع اليهود بالمغرب علي تأكيد إيجابية العلاقة

التي ظلت تربط اليهود بباقي الجماعات المكونة للمجتمع المغربي من جهة وبالسلطة المركزية من جهة ثانية ، وكان المرجع الأساسي المعتمد لدي هذه الدراسات هو مجموع الوثائق والمراسلات التي كان

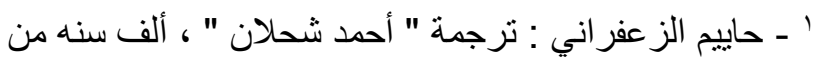

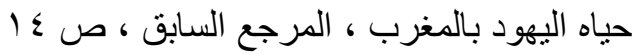

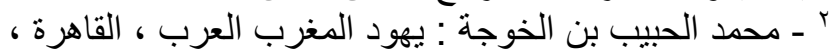

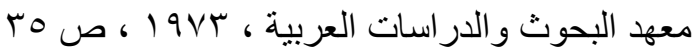


يبحث بها سلاطين المغرب التي تضمنت التزامات صريحة من جانب هؤلاء لحماية الطائفة اليهودية وضمان حقوقها ، بل ومنحها امتيازات لم تكن من حق غيرهم خاصة في مجال النشاط الاقتصادي '. وتفيد العديد من الوثائق أنه في القرنين السابع عشر والثامن عشر ظهرت فئة من كبار التجار اليهود أحنلت مكانة منميزة عبر التاريخ المعاصر ولاي سلاطين الدولة وذلك بفضل خبراتها وكبر حجم أنشطتها التجارية ، مما أدي إلي أن أطلق عليهم لقب (تجار السلطان ) وقد ساهمت هذه الفئة في استثمار أموال المخزن بل أنها لعبث دور الوسيط للدولة في تعاملتها مع الثركات التجارية الأجنبية ، وكان غالبية مشاهير تلك الفترة من ذوي الأصول الأندلسية

' ـ عبد الاله بلقزيز : الحركة الوطنية المغربية و المسألة القومية

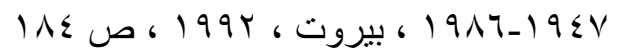

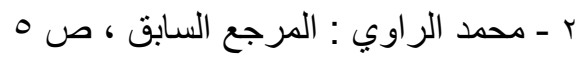
(310) 
وبحلول القرن التاسع عشر تغيرت الأوضاع

الاقتصادية يث شهدت البلاد بداية للتغلغل الأوروبي وذلك مع بداية تطبيق سياسة الحماية القنصلية التي فرضتها الدول الأوروبية علي المغرب

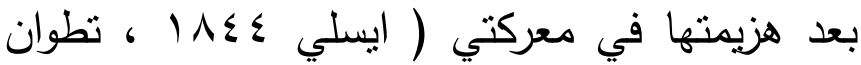
$\therefore(117$.

ويمكننا القول أن حقوق الأجانب اللذين

استقروا بالمغرب منذ بداية القرن التاسع عشر لأغراض تجارية أو دبلوماسية كانت خاضعة لأحكام الثربعة الإسلامية ، إلا أنه عندما تزايدت أعدادهم نتيجة نزايد التدخل الأوروبي طالبت القوي الغربية بالمزيد من الحرية لمواطنيها وخلال اتفاقية مدريد عام 1 1 . تم أعطاء العديد من الامتيازات لموظفي القنصليات والتجار منها الإعفاء من ضريبة الاستيراد • والتصدير

1 - عبد الاله بلقزيز : المرجع السابق ، ص عه1 | 
وبناءا عليه وضع الأجانب تحت النظام

القانوني لبلادهم الذي طبق عليهم في المغرب وسط

جاليتهم بشكل مستقل ' '

وقد تم استبعاد اليهود من تلك الامتيازات

وذلك لاعتبارهم مواطنين مغاربة من رعايا السلطان

منلمه في ذللك منل المسلمين ، لذا تم الحفاظ علي

وضعيتهم كأهل ذمة ، ولم يسمح لهم بالحصول علي

الجنسية الأوروبية ، وبالرغم من ذللك تمكنت مجموعة

منهم عن طريق بعض القناصل الأوروبيين من اكتساب وضعية ( المحمي ) مما أدي إلي تدهور العلاقة بين البهود والحكومة المغربية التي أتهمتهم بالتواطئ مع القوي الأوروبية' .

ا - محمد طحطح : الأخوه الأعداء - يهود المغرب في العصر www.hespress.com

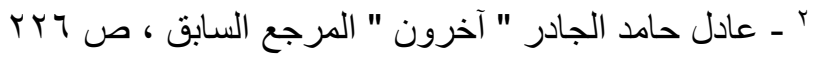


وقد ترتب عليه أن اتخذت الحكومة الإسلامية

بعض الإجراءات تجاه اليهود اللذين أصبحوا يمنلون طابورا خامسا ، هذا بالإضافة إلي بداية ظهور علامات الفكر الصهيوني خلال ذللك القرن الذي تلقي الدعم منذ ولادته من الدول الاستعمارية الغربية' .

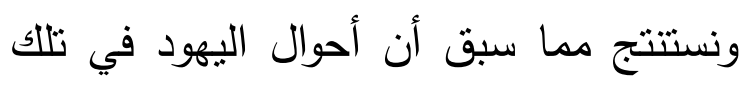
الفترة اختلفت كثيرا عن مثيلاتها فقد تميز ذلك القرن بتعاقب أحداثه التي ساهمت في تضيق الخناق علي عني المغرب حتي ظهور الأرهاصات الأولي للحماية

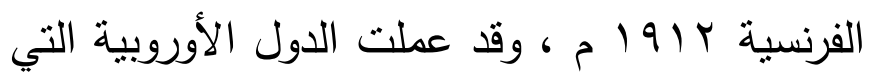
تغلغل كيانها في المملكة الثريفة علي استغلال الظروف بهدف تحقيق مصالحها الثخصية ، لذا تم إدخال العديد من اليهود بوابة الحماية القنصلية ليتمتعوا بكافة الامتيازات ومن بينها التخلص من بن بوله

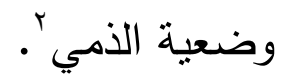

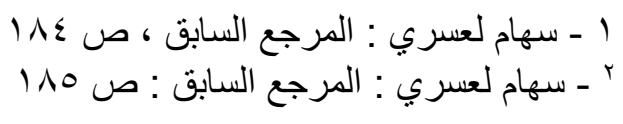


وفي عام .1100 م جاء سوء محصول القمح

المغربي وارتفاع أسعاره لكي يجبر البلاد علي الاستيراد من الخارج ، مما تسبب في سوء الأحوال الإقتصادية ، وانتنار العصابات والسرقات مدا اضطرت السلطة المخزنية للاستيراد فأخذت السفن تصل إلي العرائش ، الرباط ، وموجادير ، محملة بالقمح من فرنسا وجبل طارق وأسبانيا إلي المغرب' . وبعد انتهاء الأزمة جاءت السنوات التالية

بمحصول وفير للمغرب ، فتبدلت علميات الاستيراد إلي عمليات تصدير مما نزتب عليه أن إزدادت أهمية كلا من فاس ، جبل طارق ، كما تزايدت أعداد اليهود المشتغلين في تلك المدن والمواني ، وقد ساعدهم تماسكهم وقوة روابطهم الدينية علي

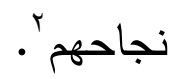

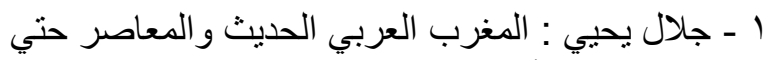

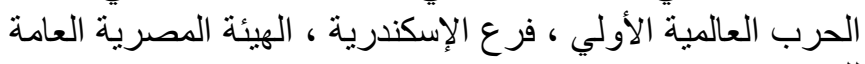

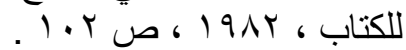

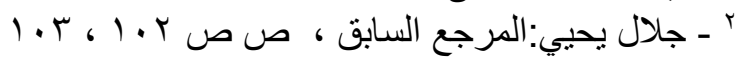


وعندما بدأت البيوت التجارية الأوروبية في

التعامل مع المغرب إضطرت لإرسال مندوبين عنها للإنثراف علي عملياتها كان علي هؤلاء المندوبين أن يحصلوا من السلطات علي تصاريح للإقامة والمتاجره ، إلا أن السلطات كانت تضع لهم العراقيل ، لذلك فضل الأجانب ترك وكلاء لهم كانت غالبيتهم يهود ، وبذا بدأ دور اليهود بسطع في السيطرة علي تجارة

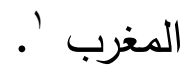
وقد ترتب عليه زيادة أرباح اليهود وثرائهم خاصة وأنهم كانوا يحصلون من اليبوت الأوروبية المالية علي رؤس الأموال اللازمة لثراء وتصدير المواد الخام ودفع الرسوم اللازمة عليها ثم يحصلون الإن

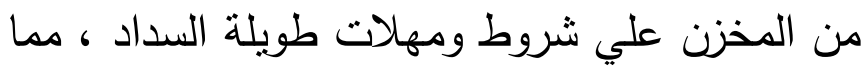

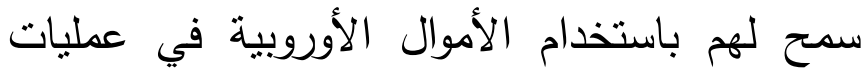
جانيية ، كما كان لتزابط اليهود ونثابه العلميات التي لئي

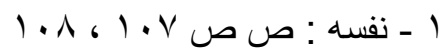


يقومون بها في جميع أنحاء حوض البحر المتوسط أثزه في أنثاء شبكة يهودية رأسمالية مغربية تتحكم في تجارة حوض البحر المتوسط بأكمله '. لذا يمكننا القول أنه بحلول منتصف القرن التاسع عثر انتقلت مراكز الأنشطة التجارية إلي المدن الساحلية التي يقيم بها رجال الأعمال والقناصل الأوروبيين فأصبحت تلك المدن مراكز اقتصادية رئيسية ، كما ظهر بين يهود المغرب شربحة اجتماعية اقتصادية جديدة اثتخل ابناءها بالتجارة وخاصة في مجال الاستيراد والتصدير ، حيث عمل هؤلاء أما كعملاء للاول الأوروبية أو شركاء في الصفقات التجارية ، وحرص هؤلاء التجار اللذين انتموا للطبقة البرجوازية علي استثمار أموالهم بالخارج أو تحويلها إلي وسائل انتاج ، كما استخل هؤلاء

' - جلال يحيي:المرجع السابق: ص ص 1 • 1 ، 9 . 1 1. 
الرعايا التي منحتهم إياها القتصليات الأجنبية في

الحفاظ علي مصالحهم وتكون ثروات طائلة '.

وكان التجار اليهود بالمغرب من أوائل اللذين

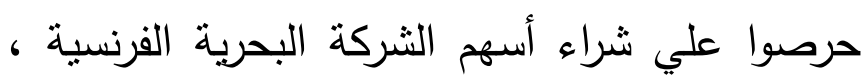

كما يمكننا القول أن معظم ممثلي قناصل الأجانب

بالمغرب حتي نهاية عقد الخمسينيات من القرن

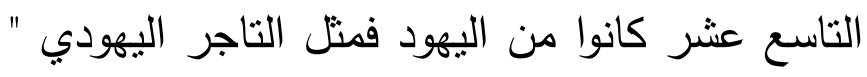

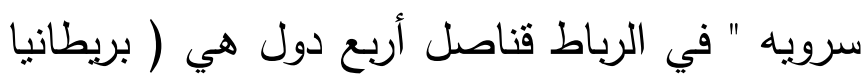

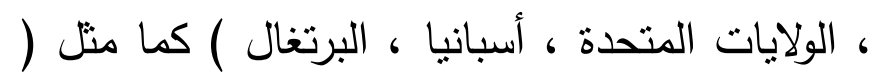

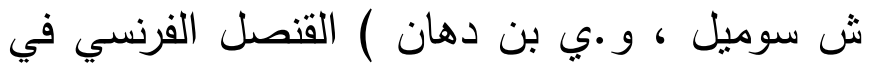

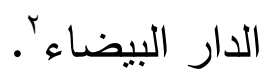

وبناءا عليه يجب أن نتفهر حقيقة أنه كلما

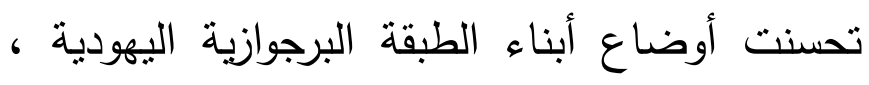

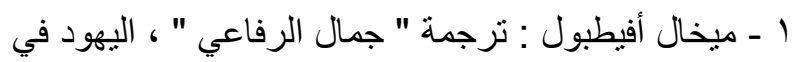

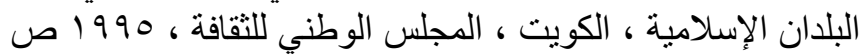

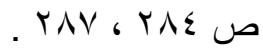
r - ميخال أفيطبول : ترجمة " جمال الرفاعي " ، المرجع السابق rイ ص : 
كانت نتدهور في المقابل أوضاع غالبية اليهود ، وذلك أما نتيجة للازمات الاقتصادية التي تمت في العصور الحديثة ، أو نتيجة لظهور النظام الرأسمالي الذي أضر بمصادر الرزق التقلدية التي اثتخل بها بعض من اليهود ، أو نتيجة لتعرض اليهود إلي بعض المضايقات من قبل السكان المغاربة اللذين كانوا يؤمنوا بأن اليهود هم المسؤلين عن تدهور

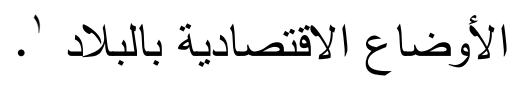
التخيرات الاجتماعية والقانونية : الاوتية

صاحب إحتلال القوي الأوروبية لبلدان المغرب العربي ، العديد من التحولات كان من أبرزها إتساع حركة الهجرة من القرية إلي المدينة ، وتزايد قوة حركة التصنيع وزيادة نسبة المواليد وظهور انماط

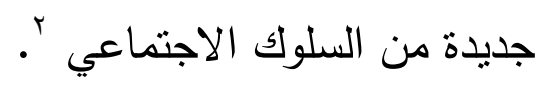

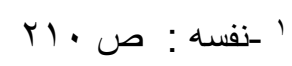
r - ميخال أفيطبول : ترجمة " جمال الرفاعي " ، المرجع

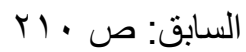


وتزودنا المراسيم والأحكام الربية ( الفتاوي

الثرعية ) بمعلومات قيمة عن حركة الهجرة الداخلية

لليهود المغاربة التي تعددت أسبابها والتي كان من

بينها سوء الأحوال الاقتصادية في بعض الفترات

بالبلاد والهروب من الجماعات وإضطهاد الحكام،

وتعد الزيارات الدينية أيضا سبيا من أسباب الهجرة

عبر المغرب ، إذ كانت تقوم عائلات بأكملها بتحمل

أعباء السفر لمسافات طوبلة لتفي بنذر قطعته علي

نفسها بزيارة قبر من قبور الأولياء الصالحين '.

ويمكننا القول أنه منذ منتصف القرن التاسع

عشر لم يعد لليهود بالمغرب وجودا في المراكز

الريفية الواقعة علي سهول جبال أطلس ، بل إتجهوا

إلي المدن الساحلية ومنها ( طنجة ، موجادير

كازابلانكا ) وقد شكل اليهود منذ عام ،1100 م ما

يتراوح بين هب \% ، ، ، \% من التعداد الكلي لسكان

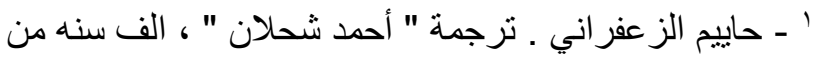

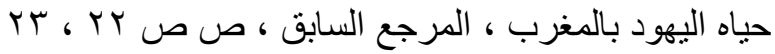




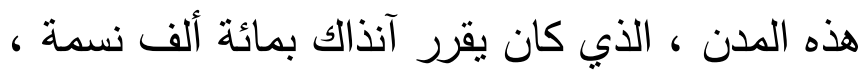

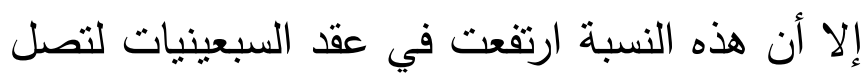

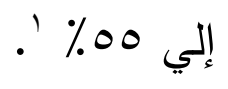

وقد شعر يهود المغرب عند إقامتهم بالددن

الجديدة بأن الحظ بدأ ييتسم لهم وأن العمل بها سيتيح لهم فرص أفضل لتحسين أوضاعهم الاقتصادية والاجتماعية ، هذا بالإضافة إلي حصول بعض الفاعل هؤلاء علي قسط وافر من المعرفة الحديثة من لإنة المؤسسات التعليمية الأوروبية التي مارست أنثطنها

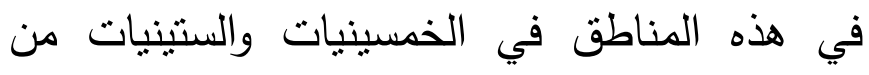
القرن التاسع عشر • الثناط في أما عن الهجرة خارج البلاد فقد كان لرغبة

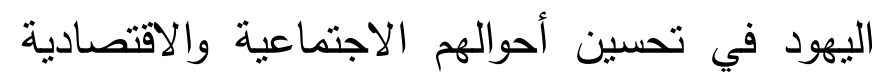

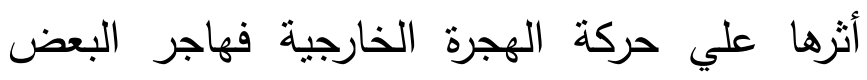
منهم إلي بعض الدول الأوروبية كما هاجر البعض البراج 1 ا ـ ميخال افيطبول ـ ترجمة " جمال الرفاعي " : المرجع السابق

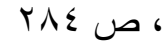


الأخر للأسباب دينية للقس ، أما الغالبية العظمي منهم ففضلوا الارتحال إلي المناطق القريبة لمنطقة جبل طارق التي تميزت بنشاطها التجاري '.

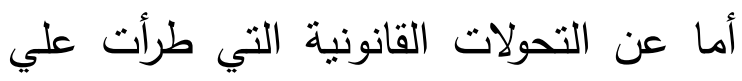

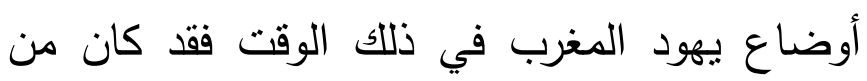
أبرز سماتها إلغاء السلطات الحاكمة لكافة القيود

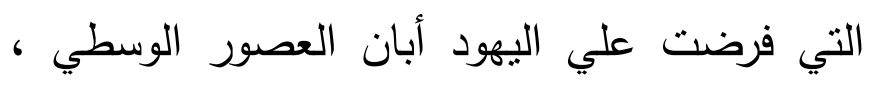

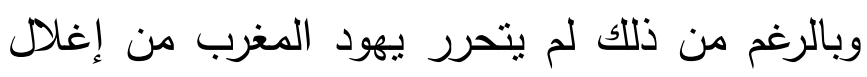
الرعوية التقليدية حيث ظلت القيادة الدينية المحافظة تسبطر علي مقاليد الأمور خاصة في أوساط اليهود

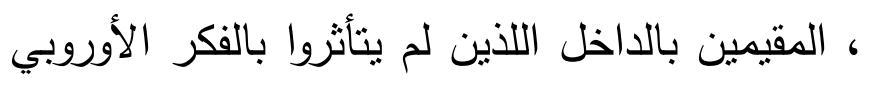

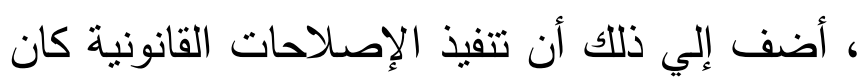
مرتبطا أيضا بمدي معارضة رجال الدين والطبقات

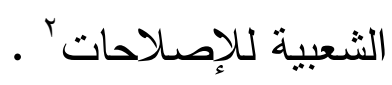

' ـ ميخال افيطبول ـ ترجمة " جمال الرفاعي " : المرجع السابق

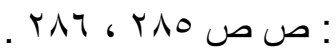

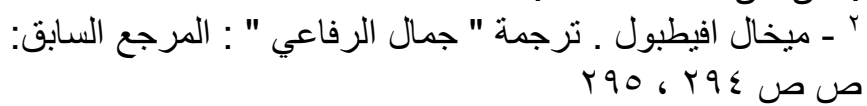




\section{علاقة يهود المغرب بأرض فلسطين :}

شهد النصف الثاني من القرن الثامن عشر

تحولات مهمة في حركة الهجرة اليهودية من بلدان

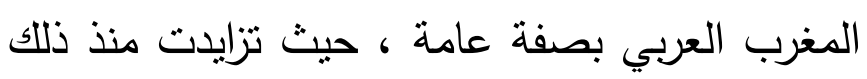

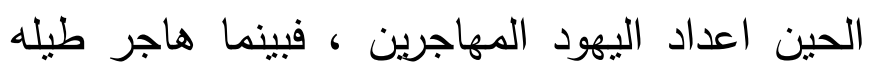

الفترات السابقة العشرات من اليهود إلي أرض الميعاد الئاد

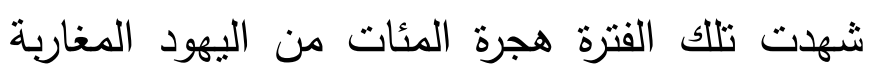

لفلسطين

وقد شملت الهجرة العديد من التغيرات كان

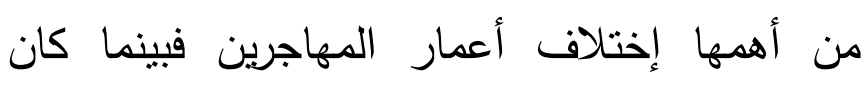

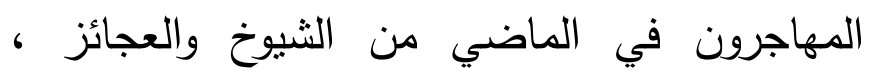

أصبحت تتراوح أعمارهم بين الثلاثثن والخمسين عاما

كما شملت التغيرات أيضا دوافع الهجرة ،

حيث كانت معظم هجرات اليهود المغاربة في البداية

لأسباب دينية أما بغرض العبادة أو لقضاء ما نبقي التجات في البالية 
من العمر هناك ، ولم يكن للاعوة الصهيونية في

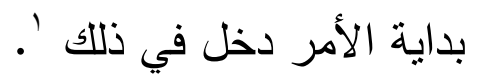

وفي نهاية القرن الثامن عشر طرأت نغيرات

علي يهود المغرب كان لها أبلغ الأثر في تغير لغنرات لغيرات

موقفهم إذاء الهجرة لفلسطين ، فقد تعرض اليهود

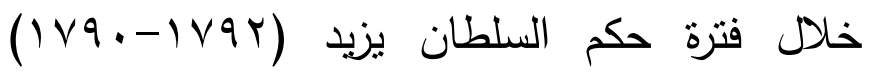

لكثير من الإضطهادات ، مما شجع شعراء اليهود

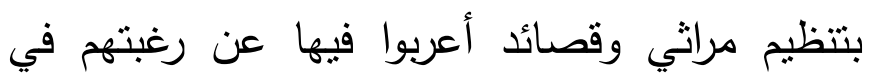

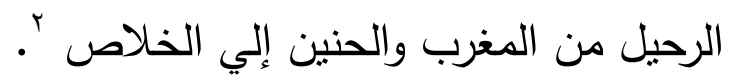

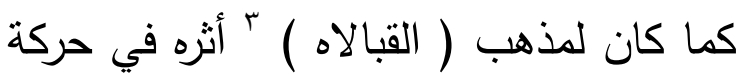

الهجرة ، ذللك المذهب الصوفي الذي انتمي إليه يهود

' ـ ميخال افيطبول : ترجمة : جمال الرفاعي ، المرجع السابق ،

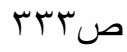

r - ميخال افيطبول ـ ترجمة " جمال الرفاعي " : المرجع السابق

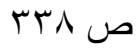

r ـ - القبالاه : كلمة آراميه تعني ما ينلقاه الخلف عن السلف وهي مزيج من الفكر الصوفي والتعاليم السرية اليهودية والاسلامية

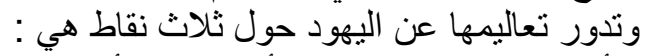
* أن الله كائن مطلق ويمكن أن يبدو في أثنياء محسو سنة كالنار

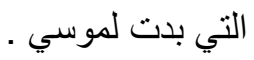


المغرب والذي نشط في زمن الحاخام ( داود حسين ) ذلك الحاخام الذي نظم الكثير من القصائد في حب بيت المقدس ، مما أدي إلي أحياء الآمال المسيحانية ، كما تزايد في ذلك الحين اهتمام الحاخامات بإعداد الحسابات لمعرفه الخلاص ، وبالرغم من أن المولي سليمان الذي خلف المولي يزيد ألغي المراسيم التي صدرت في الماضي ضد اليهود ، إلا أنه في عام 1 A.V السكن في المدن وتتيد أحياء خاصة بهم '.

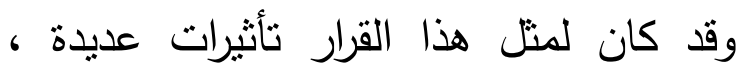
حيث أدي إلي إزدحام الأحياء اليهودية وتعرض اليهود لمشكلة سكانية حادة أسفرت عن هجرة المئات إلي القدس ، وبزيادة موجات الهجرة زادت إعداد

* أن روح الإنسان خالدة بإنتقالها بين الأجساد وهي تنتظر المسيح

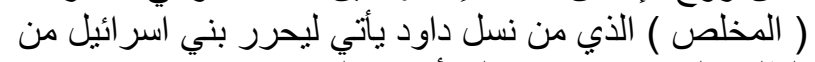

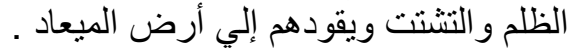

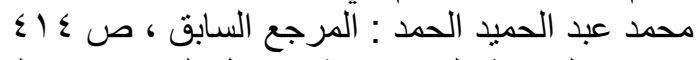

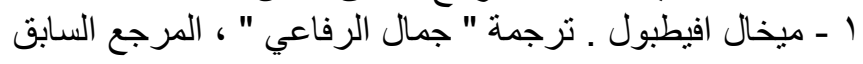
(1) 
المهاجرين مما أحدث خلل داخل المجتمع اليهودي، فضطر الحاخام ( بن ستور ) قاضي مكناس في ذلك الوقت بإصدار فتوي بمنع هجرة اليهود لفلسطين بحجة أن الهجرة تعرض الفرد وعائلته لخطر الطريق

وبناءا عليه فقد إتخذت السلطات قرارات بشأن

الحد من نشاط مذهب القبالاه لما له من أثر علي ازدياد حركة الهجرة ، إلا أن المتصوفين من اليهود كانوا بمثابة تيارا قويا ، حيث تجاوزا فتوي الحاخامات وقاموا بأثناره حمية البسطاء مما أدي إلي ازدياد إعداد

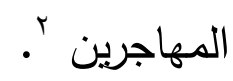

ومن الجدير بالذكر أن تيار الهجرة البهودية المغربية لفلسطين لم ينقطع عبر القرون فقد كان

1 - ميخال افبطبول : ترجمة جمال الرفاعي المرجع السابق ،

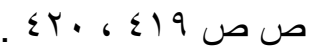
r - محمد عبد الحميد الحمد : المرجع السابق ، ص • • إع 
الطلاب يتوافدون علي ( اليشفوت )' للتعلم ، كما

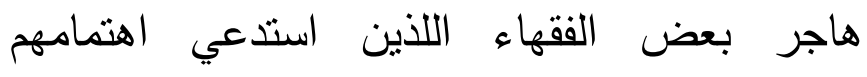
حواضر الثقافة الكبري في ( القدس ، طبرية ، صفد

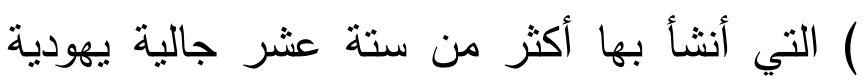

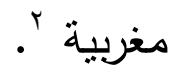

وبحلول القرن التاسع عشر كان البحث عن

الثروه والأمن والتحرر الاجتماعي والمساواة في الحقوق هي أهم أهداف تلك المرحلة ، لذا قام المئات

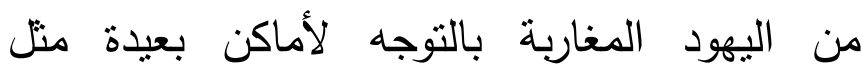

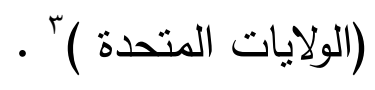

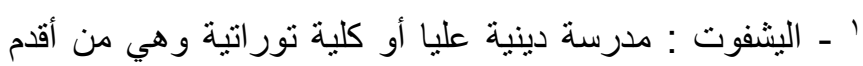

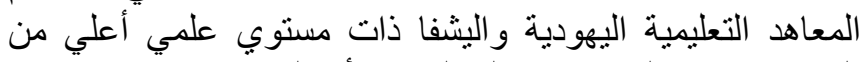

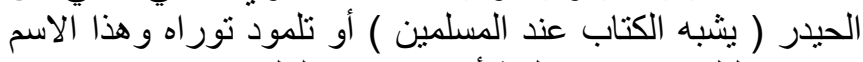

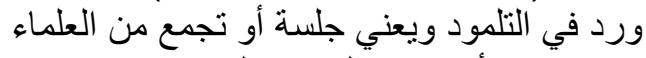

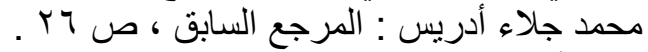

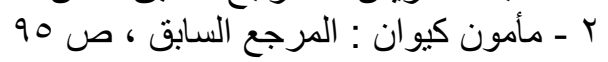

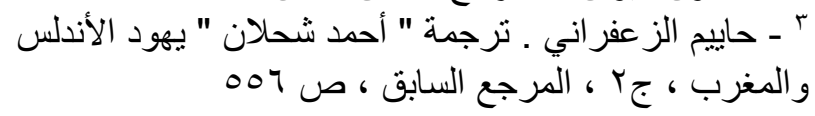


كما تزايد أيضا في العصر الحديث أعداد اليهود المهاجرين اللذين قرروا المجئ لفلسطين في ذلك الوقت لأسباب إقتصادية وكان معظمهم ينتمون إلي الطبقتين المتوسطة والدنيا حيث كان معظمهم أما باعة جائلين أو حرفيين أو تجار من ذوي الطبقة المتوسطة بالإضافة إلي أعداد من الثحاذيين '. ومن الجدير بالذكر أن العديد من أحبار يهود فلسطين كانوا يأتون إلي المغرب في ذلك الوقت وبطوفون بين أنحائه لجمع التبرعات وأرسالها لفلسطين وأيضا لنشر المعارف والوعظ وتوزيع الكتب ،وكان لهذا الدور الذي كان يقوم به الرابي المقدسي المتجول أثزه في جعل يهود الثمال الأفريقي أكثر اطلاعا من غيرهم علي ما يجري بالعالم وأكثر إتصالا بتطورات الحياة '،

' - ميخال أفيطبول ـ ترجمه " جمال الرفاعي " ، المرجع السابق ، ص سדז

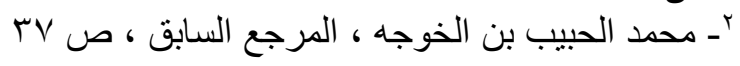


كما يمكننا القول أنه قد تزايدت قوة الرابطة

بين يهود المغرب ويهود فلسطين بعد أن أصدرت

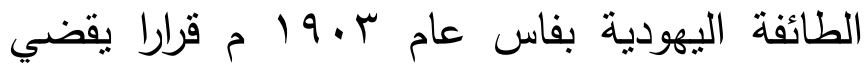

بضرورة تقديم دعم اقتصادي بشكل منتظم إلي ماني

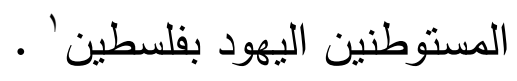

وبناءا عليه فقد عينت الطائفة بفاس لهذا لهادئ

الغرض محاسبا في كل المعابد اليهودية بفلسطين

واعتمدت علاقات اليهود المغاربة بالمسنوطنين اليهود

بفلسطين كما ذكرنا سابقا علي مبعوثي الاستيطان

اللذين كانوا يأتون من أجل جمع التبرعات ، كما كان

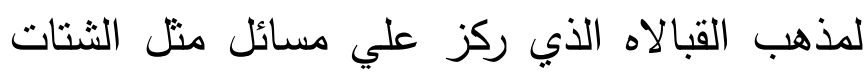

والخلاص ومجئ المسيح أثزه في نزايد قوة الرابطة

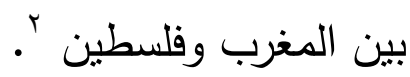

' - ميخال افيطبول ـ ترجمة " جمال الرفاعي " المرجع السابق ،

ص VTr

Y - نفسه : ص V

(328) 
وقد أدي ذلك إلي أن شهدت مناطق ( الجليل ، طبرية ) علي وجة الخصوص في بدايات القرن التاسع عشر تحولا مهما تمثل في تفضيل اليهود القادمين من بلدان الثمال الأفريقي علي سائر يهود البلدان الإسلامية ، كما تزايدت قوة ومكانة اليهود

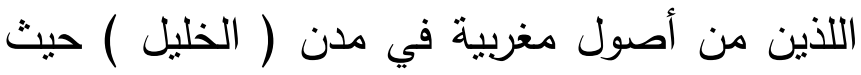
تولي أبناء العائلات اليهودية المغربية في هذه المدن القيادة الدينية.

كما كان للرعايا الأوروبية وخاصة الفرنسية التي حظيت بها بعض العائلات المهاجرة منل عائلة (عبوا) التي تولي أبناءها القبادة ( بصفد ) أثرها في بنان

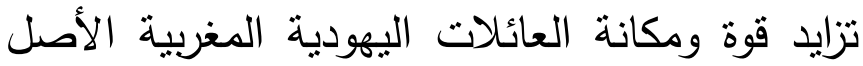
بفلسطين ومن الملاحظ أن معظم مهاجري المغرب استقروا بالقدس ، وكان لهم دور فعال في تطوير الاستيطان اليهودي في مرحلة لاحقة '.

' ـ ميخال افيطبول ـ ترجمة " جمال الرفاعي " ، المرجع السابق

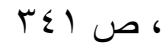


وكان من بين العوامل التي ساعدت اليهود

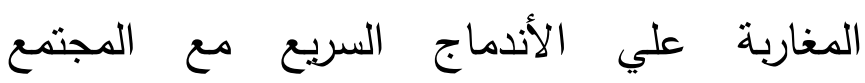
الفلسطيني أن غالبية المهاجرين كانوا من الثباب اللذين اثتنغلوا بالتجارة وبالمهن اليدوبة الأمر الذي ساعدهم علي النجاح في إقامة علاقات اقتصادية قوية مع السكان العرب بفلسطين وعلي الرغم من ذلك يوجد لدينا صعوبة في التعرف علي التعداد الدقيق لليهود المغاربة ، اللذين هاجروا واستوطنوا بفلسطين خلال القرن التاسع عثر ، فمن المعروف أنه قد هاجر لفلسطين خلال الفترة . .119 - 1199 بضع مئات من البهود اللذين أحدثوا طفرة في مسيرة الانتاج وفي الأنشطة التجارية والصناعية بفلسطين ، وقد أدي ذلك إلي تزايد أهمية الهجرة من بلدان المغرب • العربي لفلسطين

وبناءا عليه فقد شهدت نهايات القرن التاسع عثر تزايد تدريجي في تعداد الهجرة المغربية 
لفلسطين إلي أن شكلت حوالي ربع أبناء الطائفة السفاردية في القس في ذلك الوقت . كما شهدت الطائفة اليهودية المغربية بفلسطين خلال هذه الفترة تطورات عديدة بفضل الأنشطة التي قام بها الحاخام ( داود بن شععون )

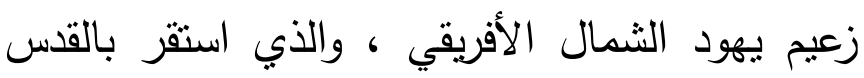

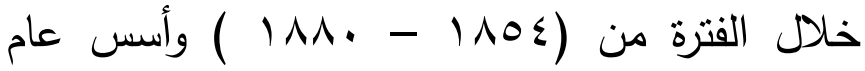
INTV م للمغاربة حي ( محسنية يسرائيل ) كما يرجع إلبه الفضل في تأسيس ملجأ لفقراء الطائفة

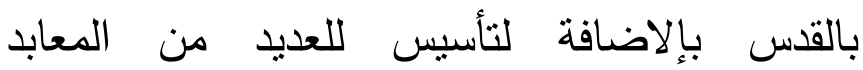
والمؤسسات التعليمية اليهودية' .

وفي النهاية يمكننا القول أنه في •ب أذار عام r| 19 ا م وبعد حروب طاحنه استطاعت فرنسا

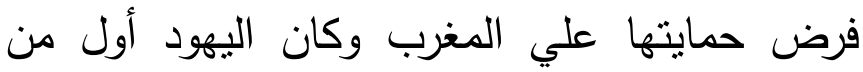
استبشروا خيرا بالاحتلال كما ساهموا في العديد من

' - ميخال افبطبول : ترجمة جمال الرفاعي ، مرجع السابق ، 
التغيرات والتحولات التي طرأت علي البلاد في ذلك

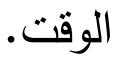




\section{الخاتمة :}

في ضوء ما تقدم من استعراض للجوانب المختلفة للواقع السياسي والاجتماعي وأيضا الاقتصادي والثقافي ليهود المغرب خلال فترة ما قبل الحماية الفرنسية يمكننا إبراز أهم نتائج البحث فيما يلي: 1- إن التاريخ العربي الإسلامي وحضارته الثقافية والسياسية قامت علي أساس من العدل والمساواة والتسامح مع الطوائف الدينية الأخري . r- أوضحت الدراسة أن يهود المغرب لعبوا دورا فعال في مختلف جوانب الحياة بالمغرب وشاركوا في مختلف الأنشطة الاقتصادية والاجتماعية والثقافية ، وذلك بحرية تامة ودون شرط أو قيد ، فلم تصدر السلطات الحاكمة تجاههم أي قرار يمنعهم من مزاولة مهنة أو حرفة معينة

r- تمتع يهود المغرب بحق المواطنة المغربية الكاملة فقد كانوا جزءا لا يتجزأ من نسيج المجتمع المغربي ، كما لها لهن تمتعوا بحماية رجال البلاط الحاكمة بالإضافة إلي تمتعهم

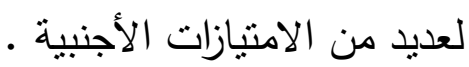


ع-امتلاك يهود المغرب نراثا ثقافيا غنيا إمتزج بالثقافة

والتقاليد العربية ، الإسـامية ، مما عبر عن الإندماج

الكامل داخل المجتمع المغربي بين الأكثرية والأقلية . 


\section{قائمة المصادر والمراجع}

رسائل جامعية :

- زينب حسن أبو زيد : اليهود في الأندلس في

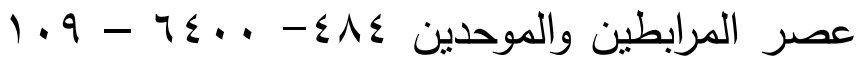

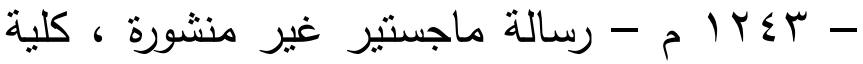
الآداب ، جامعة القاهرة ، V. . . . . ل البحوث والمقالات : عادل حامد الجادر : يهود الأقطار العربية ، بغداد ، بحوث الندوه التي عقدها مركز الدراسات الفلبسطينية $.199 .619 \mathrm{NV} / 1 \leqslant-14$

\section{المراجع العربية :}

- جلال يحيي : الدغرب العربي الحديث والمعاصر حتي الحرب العالمية الأولي ، فرع الإسكندرية ،

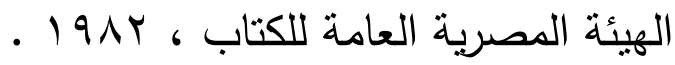


- جمال حمدان : اليهود انتردبولوجيا ، القاهرة ، دار

الهلال ، العدد ros ، 1997

- حاييم الزعفراني : ثرجمة أحمد شحلان ألف سنه ، من حياة اليهود بالمغرب - تاريخ - ثقافة - دين لتربن الرباط ، مرسم ، $191 \mathrm{VV}$

- - حاييم الزعفراني : ترجمة أحمد شحلان يهود الأندلس والمغرب ، جا ، جr ، الرباط ، النجاح

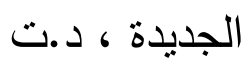

- دوم لاندو : تاريخ المغرب في القرن العشرين ، . 191.

- زبيدة محمد عطا : اليهود في العالم العربي ، القاهرة ، عين الدراسات والبحوث الإنسانية ، ب . ب. - سناء عبد اللطيف : الجيتو اليهودي دراسة للاصول الفكرية والثقافية للمجتمع الإسرائليي ، دمثق ، دار القلم ، 1999

- سام برنر : اليهود العرب عالم تم محوه وصفحات ازيلت دن كتب التاريخ ، د ن ، د.ت (336) 
- سوزان السعبد يوسف : المعتقدات الثعبية حول

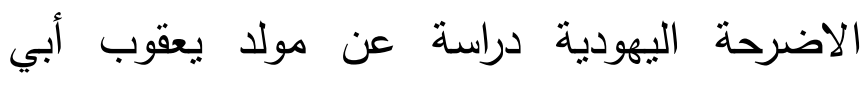

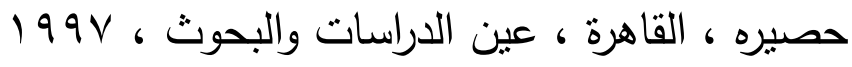

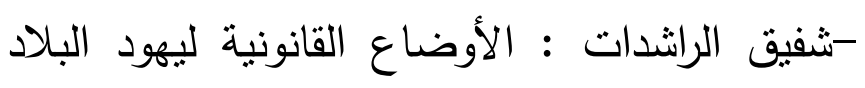
العربية ، القاهرة مطبوعات الامانة العامة لاتحاد الاداد الإداد

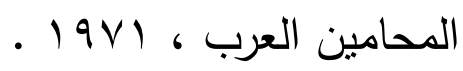
- عبد الآله بلقزيز : الحركة الوطنية المغربية

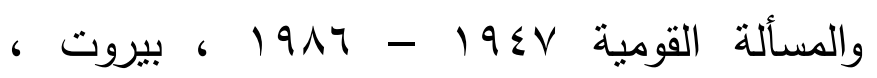
1994

- عبد الجليل شلبي : اليهود واليهودية، القاهرة ، دار أخبار اليوم ، 1997 - عطية القوصي : اليهود في ظل الحضارة الئارة الإسلامية ، جامعة القاهرة ، مركز الدراسات الثرقية

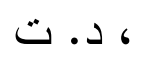

- مأمون كيون : اليهود في الثرق الأوسط الخروج الأخير من الجيتو الجديد ، القاهرة، الأهلية للنشر ، الأسطرد .1997 
- ماهر سمك : اليهود في المغرب ، القاهرة ، دار

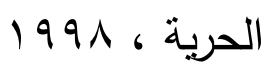

- محمد الحبيب بن الخواجة : يهود المغرب العربي

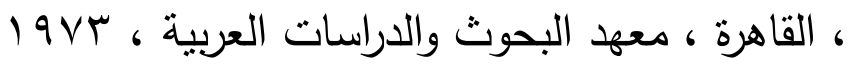
- محمد جلاء أدريس : مؤثرات عربية وإسلامية في الأدب الإسرائيلي ، القاهرة ، دار الثقافة ، ب . . ب - محمد عبد الحميد الحمد : دور اليهود في

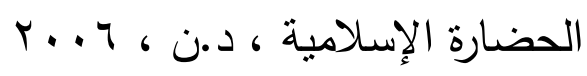
- ميخال افيطبول : اليهود في البلد الإسلامية . 1100 - 190 ، الكويت ، المجلس الوطني للتقافة والفنون والآداب ، 1990 . - هدي درويش : اسرار اليهود المستتصرين في الأندلس دراسة اليهود المارانوس ، القاهرة ، عين

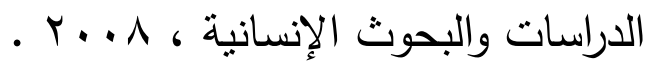
- هدي درويش : الصرلاه في الثرائع القديمة والرسالات السماوية ، اليهود ، المسيحية، الإسلام ، 
القاهرة ، عين الدراسات والبحوث الإنسانية

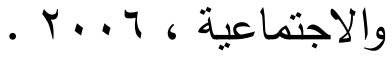




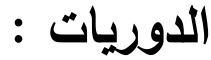

- إبراهيم بيصون : اسبانيا في تاريخها - المسيحيون

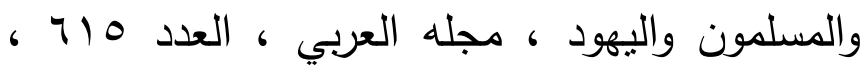

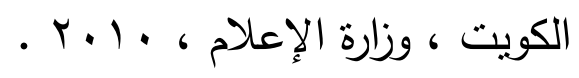

- إيمان عبد الرحمن : التعايش السلمي للمسلمين مع أهل الذمة في الدولة المرابطية في عصر علي بن بن

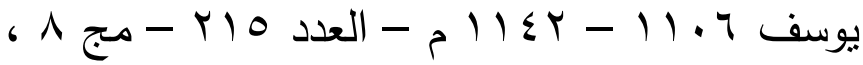
مجله كلية العلوم الإنسلامية ، جامعة الموصل ، r. I $\leqslant$ - باب سيدي : يهود مغاربة ، مجلة شؤون فلسطينية

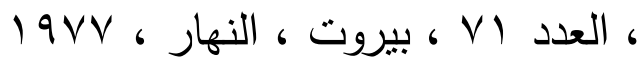
- دمية عبد الرحيم : يهود المغرب العربي في اسرائيل ، مجله شؤون فلسطينية ، بيروت منظمة التحرير الفلسطينية ، 1911 .

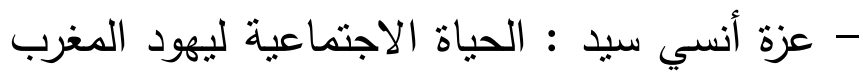
من منتصف القرن التاسع عثر حتي أوائل القرن 
العشرين ، دورية علمية محكمة ، العدد الثاني ، جr

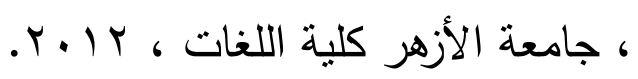

- علي عبد السلام سيد أحمد : ورقات تاريخية عن حياة البربر الدينية والخلفية في المغرب العربي ، المجلة التاريخية المصرية ، مج • ب ، اب ، القاهرة

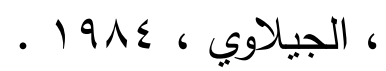




\section{معلومات شبكة الانترنت :}

- آسفي مدينة ليهود بدون صلاح - مجلة سفال

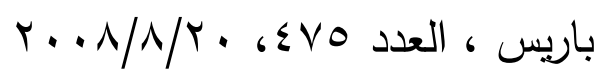

www.safipress.com

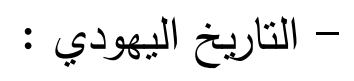

www.jimenaexperienc.org

- محمد الرواي : اليهود المغاربة ، الثرق الأوسط ،

$$
\text { العدد Irov }
$$

www.asharqalawsat.com

- توزيع اليهود في العالم العربي : المعرفة ، قسم

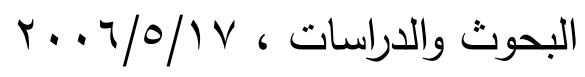

www.aljazeera.net

- جهاد فاضل : اليهود في المغرب العربي ، جريدة

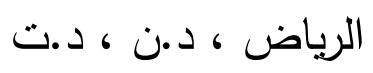

www.alrigabhi.com

- سهام لعسري : نبذة عن اليهود في تاريخ المغرب

www.anfasse.org 


$$
\text { - محمد طحطح : الأخوه الأعداء يهود المغرب في }
$$

WwW.hespress.com

$$
\text { - مغاربة يهود : ويكيبيديا الموسوعة الحرة ، با • r r }
$$

www.news.bbc.com

- اليهود المغاربة - تاريخهم - تحقيق الفجر -

. T. T 